Pushing High-Heat-Load Optics to the Limit*

\author{
P. B. Fernandez \\ Advanced Photon Source \\ Argonne National Laboratory \\ Argonne, IL 60439
}

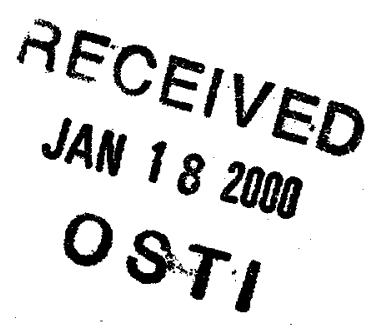

October 1999

The submitted manuscript has been created by
the University of Chicago as Operator of
Argonne National Laboratory ("Argonne") under
Contract No. W-31-109-ENG-38 with the U.S.
Department of Energy. The U.S. Government
retains for itself, and others acting on its behalf,
a paid-up, nonexclusive, irrevocable worldwide
license in said article to reproduce, prepare
derivative works, distribute copies to the public,
and perform publicly and display publicly, by
or on behalf of the Government.

Invited paper to be published in the Proceedings of the $11^{\text {th }}$ U.S. National Synchrotron Radiation Instrumentation Conference (SRI'99), Stanford, CA, October 13-15, 1999.

\footnotetext{
*This work is supported by the U.S. Department of Energy, Basic Energy Sciences, Office of Science, under contract \#W-31-109-ENG-38.
} 


\section{DISCLAIMER}

This report was prepared as an account of work sponsored by an agency of the United States Government. Neither the United States Government nor any agency thereof, nor any of their employees, make any warranty, express or implied, or assumes any legal liability or responsibility for the accuracy, completeness, or usefulness of any information, apparatus, product, or process disclosed, or represents that its use would not infringe privately owned rights. Reference herein to any specific commercial product, process, or service by trade name, trademark, manufacturer, or otherwise does not necessarily constitute or imply its endorsement, recommendation, or favoring by the United States Government or any agency thereof. The views and opinions of authors expressed herein do not necessarily state or reflect those of the United States Government or any agency thereof. 


\section{DISCLAIMER}

Portions of this document may be illegible in electronic image products. Images are produced from the best available original document. 


\title{
Pushing High-Heat-Load Optics to the Limit
}

\author{
P.B. Fernandez \\ Advanced Photon Source, Experimental Facilities Division \\ Argonne National Laboratory, Argonne, Illinois 60439
}

\begin{abstract}
A cryogenically cooled silicon monochromator and a water-cooled diamond monochromator have been tested under twice the standard power load conditions at the Advanced Photon Source. Both monochromators performed satisfactorily under these extreme power loads (several hundred watts of incident power and up to $300 \mathrm{~W} / \mathrm{mm}^{2}$ of incident normal peak power density). The experimental data and the parameters derived to predict the performance limits of the cryogenic silicon monochromator are presented.
\end{abstract}

\section{INTRODUCTION}

Insertion devices at third-generation synchrotron radiation sources are capable of delivering $\mathrm{x}$-ray beams with total power in excess of $1 \mathrm{~kW}$ and heat flux of several hundreds of $\mathrm{kW} / \mathrm{mrad}^{2}$. The unprecedented intensity of these beams presents a challenge for the thermal management of white beam beamline components, such as $\mathrm{x}$-ray mirrors and single-crystal monochromators. To preserve the high quality of the incident beam, thermal deformations in the optical components must be less than $1-2 \mu \mathrm{rad}$ for mirrors, while the deformation of the diffraction planes in crystals should be much less than the Darwin width of the reflection, typically several $\mu \mathrm{rad}$. These distortions include bowing due to the thermal gradient perpendicular to the surface of the optic, thermal mapping distortion due to the temperature gradient along the surface, and, in the case of single-crystal optics, the change in lattice constant due to thermal expansion $(1,2)$.

The thermal deformation induced by the $\mathrm{x}$-ray white beam is proportional to the power and surface power density absorbed by the cooled optic, and to the ratio $\alpha / k$, where $\alpha$ is the coefficient of thermal expansion and $\mathrm{k}$ is the thermal conductivity of the material. Both $\alpha$ and $\mathrm{k}$ depend on the overall temperature of the optic; the thermomechanical properties of materials tend to worsen with increased temperature. The thermal deformation is then also proportional to the overall temperature, which in turn is inversely proportional to the cooling efficiency. The possible solutions to the high-heat-load problem have thus focused on: geometrical approaches to reduce the absorbed power and surface power density; the wise choice of materials and/or 
operating conditions to maximize the ratio $\alpha / \mathrm{k}$; and improvements to the cooling efficiency through enhanced heat exchangers and cooling fluids. In this paper we will present the successful thermal management solutions for crystal monochromators implemented at the Synchrotron Radiation Instrumentation Collaborative Access Team (SRI-CAT) beamlines at the Advanced Photon Source (APS) for operation at $100 \mathrm{~mA}$ of stored beam current, and the possible approaches for enhanced operations (higher stored beam current, longer insertion devices, or smaller magnetic gaps).

\section{THERMAL MANAGEMENT AT THE APS}

\section{Undulator Thermal Load}

Undulator A is the 3.3-cm-period undulator installed in the majority of the insertion device beamlines at the APS. The undulator is $2.4 \mathrm{~m}$ long, with 72 magnetic periods, and has a maximum deflection parameter $\mathrm{K}$ of 2.57 at a minimum gap of $10.5 \mathrm{~mm}$. At this minimum gap and at $100 \mathrm{~mA}$ of stored beam current, the total power delivered by the undulator is $5 \mathrm{~kW}$, with peak power density at normal incidence of $170 \mathrm{~W} / \mathrm{mm}^{2}$ at $30 \mathrm{~m}$ from the source. A judicious choice of white beam slits can substantially reduce the heat load on the beamline components: 2 -mm-wide horizontal slits by $1-\mathrm{mm}$-tall vertical slits at $30 \mathrm{~m}$ from the source will transmit close to $80 \%$ of the undulator central radiation cone at the third harmonic energy of $9.8 \mathrm{keV}(\mathrm{K}=2.57)$, while cutting down the power incident on the first optic to $320 \mathrm{~W}$. The high-heat-load problem, for APS operations at $100 \mathrm{~mA}$ of stored beam current, is then how to maintain the performance of white beam optical components subject to hundreds of watts of power and over $150 \mathrm{~W} / \mathrm{mm}^{2}$ of normal incidence peak power density.

Higher intensity $\mathrm{x}$-ray beams could be delivered in any of the following enhanced operations scenarios: increasing the stored beam current; installing two 2.4-m-long undulators in series or a 5-m-long undulator in the insertion device beamlines; or reducing the insertion device minimum magnetic gap by installing a smaller vacuum chamber in the straight section. The power load on the first optical component will increase linearly with the stored beam current, and it will double if two undulators are used in series or if the undulator length is doubled. A smaller vacuum chamber will result in a reduction in the minimum undulator magnetic gap from $11.5 \mathrm{~mm}$ to $8 \mathrm{~mm}$, with a corresponding $40 \%$ increase of the power load on the first optical component.

\section{Crystal Monochromators}

The thermal management solutions for high-heat-load monochromators at the APS focus on the enhancement of the ratio $\alpha / \mathrm{k}$ of the single-crystal monochromator material. Table 1 lists $\alpha / \mathrm{k}$ at room temperature and at $100 \mathrm{~K}$ for silicon and diamond. The ratio $\alpha / \mathrm{k}$ for silicon at cryogenic temperature is 35 times smaller than at room 
TABLE 1. Ratio $\alpha / \mathrm{k}$ for silicon and diamond at 100 and $300 \mathrm{~K}$. The range for diamond corresponds to the different types of diamonds: the lowest values are for type lla diamond (virtually impurity free), while the high end of the range corresponds to type I diamond (up to $0.1 \%$ nitrogen contamination). Note that $\alpha$ for silicon becomes negative below $125 \mathrm{~K}$.

\begin{tabular}{c|c|c}
\hline Temperature & \multicolumn{2}{|c}{$\alpha / \mathbf{k}\left(10^{-6} \mathrm{~cm} / \mathrm{W}\right)$} \\
\hline $300 \mathrm{~K}$ & Silicon & Diamond \\
$100 \mathrm{~K}$ & 1.6 & $0.1-0.04$ \\
\hline
\end{tabular}

temperature, so we expect that the thermal performance of liquid-nitrogen-cooled silicon will be commensurately better than that of water-cooled silicon. On the other hand, the superb thermomechanical properties of diamond result in a ratio $\alpha / \mathrm{k}$ at room temperature that is comparable to cryogenic silicon. Thus, the two options for highheat-load monochromators pursued at the APS are liquid-nitrogen-cooled silicon and water-cooled diamond crystals. Both of these options have been successfully implemented at the European Synchrotron Radiation Facility in Grenoble, France (3), and are planned for beamlines at the Super Photon ring SPring-8 in Harima, Japan (4).

\section{Cryogenic silicon monochromator}

The High Heat Load Optics group at the APS has successfully developed a liquidnitrogen-cooled silicon monochromator that is capable of accepting the full undulator A central radiation cone at $100 \mathrm{~mA}$ of stored beam current. The silicon crystal is directly cooled, with liquid nitrogen flowing through cooling channels drilled in the crystal. The seal between the crystal and the invar manifold is achieved using indium-coated C-rings. Diffraction can occur on a recessed thin web in the center of the crystal or on the thick sections just off center. Details of the design and experimental results at $100 \mathrm{~mA}$ of stored beam current can be found in reference 5 .

Recently we had the opportunity to install a second undulator A in the SRI-CAT sector 1 insertion device beamline. We then tested the performance of the cryogenically cooled silicon monochromator under the power load delivered simultaneously by both undulators. This configuration was equivalent to operations with one undulator at $200 \mathrm{~mA}$ of stored beam current. The (111) silicon crystal that we tested had a slightly different design than that in reference 5 : the thin central web was not recessed with respect to the (111) surface but at the same level as the thick portions of the crystal. This design modification results in easier fabrication of the crystal at the expense of poorer thermal performance of the thin section (6).

The silicon monochromator was tested for several beam sizes, from $1.5 \mathrm{~mm} \mathrm{H}$ by $0.5 \mathrm{~mm} \mathrm{~V}$ to $3 \mathrm{~mm} \mathrm{H}$ by $2 \mathrm{~mm} \mathrm{~V}$. The smaller size corresponds to the full-width-halfmaximum (FWHM) of the undulator central radiation cone at the position of the white beam slits, while the larger size is the maximum allowed by the front-end window. Details of the experiment can be found in reference 6 . 
To gauge the thermal performance of the monochromator, we tracked the rocking curve FWHM of the Si(333) and higher order reflections as a function of the absorbed power and surface power density. An increase in rocking-curve width is linked to increasing thermal slope errors (1). We found that the performance of the monochromator deteriorated for the largest beam size, i.e., highest incident power. Figure 1 shows data taken on the thick section of the crystal, for an assortment of beam sizes, undulator gaps, and monochromator energy combinations. The rocking curve FWHM of the higher order reflections (I1 FWHM) is plotted as a function of the calculated power absorbed by the crystal and of the calculated average surface power density absorbed in the first 10 microns of the crystal. Recall that the thermal deformation is a function of the ratio $\alpha / \mathrm{k}$ and of the absorbed surface power density. We expect the total absorbed power to be a relevant parameter to describe the data since the ratio $\alpha / \mathrm{k}$ is a strong function of the temperature, and the temperature will be affected by the power absorbed in the silicon. The abscissa gives an indication of the absorbed surface power density. The hyperbola-like line in the plot has been empirically drawn to separate the regions of good thermal performance (FWHM $<2$ ") from that of increasing thermal slope errors. To assess if this crystal would perform adequately with one undulator at $200 \mathrm{~mA}$ of stored beam current, we calculated the expected absorbed power and average absorbed power density near the surface for a $1.5 \mathrm{~mm} \mathrm{H}$ by $0.5 \mathrm{~mm} \mathrm{~V}$ beam as the undulator is tuned for peak brilliance in the

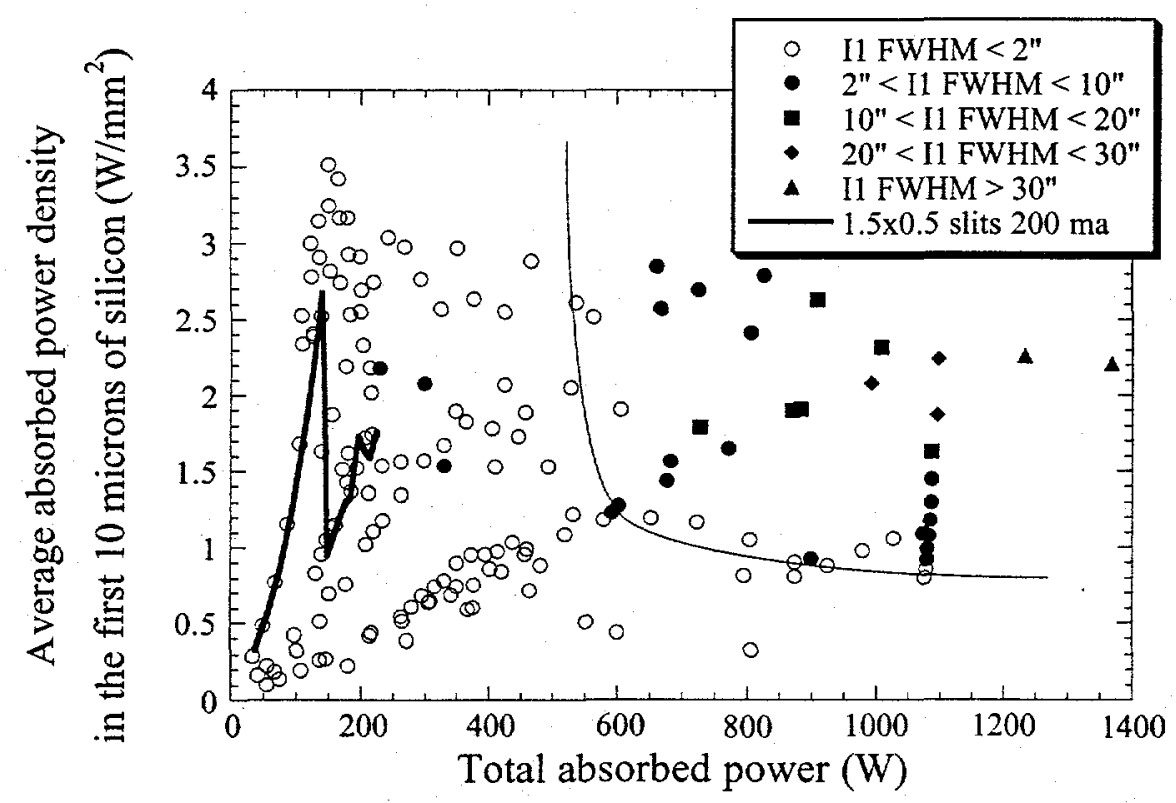

FIGURE 1. Rocking curve FWHM of the Si(333) and higher order reflections (I1 FWHM) as a function of the calculated total power absorbed by the crystal and of the calculated average surface power density absorbed in the top 10 microns of silicon. The three data points that exceed 2 " for total absorbed power less than $400 \mathrm{~W}$ correspond to II FWHM $\leq 2.1 "$. 
energy range 7 to $20 \mathrm{keV}$. This undulator 'tuning curve' lies in the region of expected good thermal performance and indicates that the cryogenically cooled silicon monochromator will perform adequately for enhanced APS operations at $200 \mathrm{~mA}$ (6).

\section{Water-cooled diamond monochromator}

Water-cooled diamond monochromators have been successfully implemented at the APS for operations at $100 \mathrm{~mA} \mathrm{(7).} \mathrm{The} \mathrm{double-crystal} \mathrm{monochromator} \mathrm{consists} \mathrm{of} \mathrm{two}$ synthetic diamond plates. The first crystal is indirectly water cooled through edge contact with a nickel-plated, integrally cooled copper holder; good thermal contact between the diamond and the copper is achieved through a thin layer of galliumindium eutectic. The diamond straddles a $3-\mathrm{mm}$-wide trough, which is cut in the holder to allow for transmission of the undiffracted undulator beam; a detailed description can be found in reference 8 .

We tested this monochromator design under the thermal load produced by the two undulators $\mathrm{A}$ in tandem. The diamond (111) plates were synthetic type IIa manufactured by Sumitomo Electric, Japan. The plates were approximately $10 \mathrm{~mm}$ by $5 \mathrm{~mm}$ by $0.5 \mathrm{~mm}$ in size and exhibited a mosaic spread/strain of the order of 1 to $3 "$ ". The incident beam size was $2 \mathrm{~mm} \mathrm{H}$ by $1.2 \mathrm{~mm} \mathrm{~V}$, which corresponds to $80 \%$ of the undulator odd-harmonic central radiation cone. The power and normal peak power density incident on the diamond were $609 \mathrm{~W}$ and $270 \mathrm{~W} / \mathrm{mm}^{2}$, respectively, when both

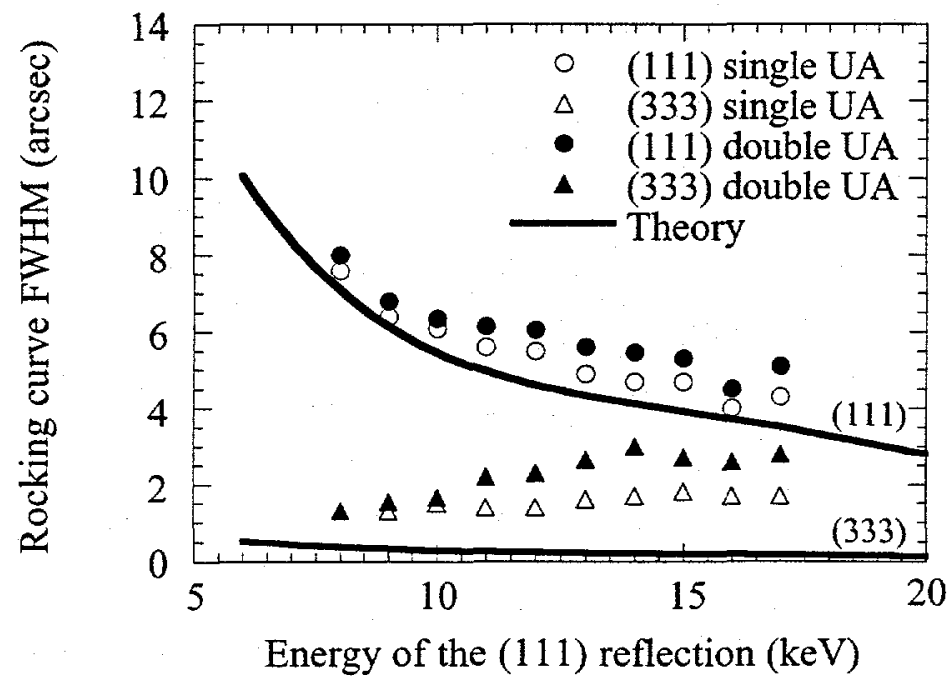

FIGURE 2. Rocking curve FWHM of the (111) and (333) reflections as a function of the energy of the (111) reflection for the water-cooled diamond monochromator. Data were taken with a single undulator $\mathrm{A}(\mathrm{UA})$ at $11 \mathrm{~mm}$ gap, and with both undulators at $11 \mathrm{~mm}$ gap. Deviations from theory are due to a combination of the mosaic spread/strain of the crystals and thermally induced mounting strains. 
undulators were at $11 \mathrm{~mm}$ gap and the storage ring current was $83 \mathrm{~mA}$. With both undulators at $11 \mathrm{~mm}$ gap, the maximum power and surface power density absorbed by the first crystal were $107 \mathrm{~W}$ at $17 \mathrm{keV}$ and $12 \mathrm{~W} / \mathrm{mm}^{2}$ at $8 \mathrm{keV}$, respectively. Figure 2 shows the rocking curve FWHM of the (111) and (333) reflections as a function of energy for a single undulator at $11 \mathrm{~mm}$ gap, and for both undulators at $11 \mathrm{~mm}$ gap. The deviations of the single undulator data from theory are due to the intrinsic mosaic spread/strain of the diamond crystals. The data show a slight increase in the FWHM for both undulators at $11 \mathrm{~mm}$ gap. This slight increase is probably due to thermally induced mounting strains and not to thermal strain in the first crystal. We expect that the water-cooled diamond monochromator will perform well for APS operations with a single undulator at $200 \mathrm{~mA}$ of stored beam current.

\section{CONCLUSIONS}

We have found that the total absorbed power and power density absorbed near the surface are relevant parameters to predict the thermal performance of the cryogenic silicon monochromator. Double-undulator high-heat-load tests show that both the liquid-nitrogen-cooled silicon and water-cooled diamond monochromators will perform well under higher power load operating conditions at the APS.

\section{ACKNOWLEDGMENTS}

The work presented in this paper has been carried out by members of the High Heat Load Optics group at the APS: W.K. Lee, P.B. Fernandez, D.M. Mills, G. Tajiri, and L. Assoufid. The assistance of the SRI-CAT sector 1 staff is gratefully acknowledged. Use of the Advanced Photon Source was supported by the U.S. Department of Energy, Basic Energy Sciences, Office of Energy Research, under Contract No. W-31-109Eng-38.

\section{REFERENCES}

1. Smither, R.K, Nucl. Instrum. Methods A 291, 286-299 (1990).

2. Yamaoka, H., Tong, X., Uruga, T., and Sakurai, Y., SPIE Proceedings 1739, 522-527 (1993).

3. Freund, A.K., SPIE Proceedings 2515, 445-457 (1995).

4. Uruga, T., Kimura, H., Kohmura, Y., Kuroda, M., Nagasawa, H., Ohtomo, K., Yamaoka, H., Ishikawa, T., Ueki, T., Iwasaki, H., Hashimoto, S., Kashihara, Y., and Ouki, K., Rev. Sci. Instrum. 66, 2254-2256 (1995).

5. Rogers, C.S., AlP Conf. Proc. 417, 61-65 (1997).

6. Lee, W.-K., Fernandez, P.B., and Mills, D.M., submitted to J. Synchrotron Rad. (1999).

7. Fernandez, P.B., Graber, T., Lee, W.-K., Mills, D.M., Rogers, C.S., and Assoufid, L., Nucl. Instrum. Methods A 400, 476-483 (1997); Alp, E.E., private communication (1999).

8. Fernandez, P.B., Graber, T., Krasnicki, S., Lee, W.-K., Mills, D.M., Rogers, C.S., and Assoufid, L., AIP Conf. Proc. 417, 89-94 (1997). 